\title{
Use of genetically engineered bone marrow-derived mesenchymal stem cells for glioma gene therapy
}

\author{
SHINJI AMANO ${ }^{1}$, SHAOYI LI ${ }^{1,3}$, CHUNYU GU $^{1}$, YUN GAO ${ }^{1}$, SHINICHIRO KOIZUMI ${ }^{1}$, \\ SEIJI YAMAMOTO ${ }^{2}$, SUSUMU TERAKAWA ${ }^{2}$ and HIROKI NAMBA ${ }^{1}$ \\ ${ }^{1}$ Department of Neurosurgery and ${ }^{2}$ Photon Medical Research Center, Hamamatsu University \\ School of Medicine, 1-20-1 Handayama, Higashi-ku, Hamamatsu 431-3192, Japan
}

Received July 24, 2009; Accepted September 10, 2009

DOI: 10.3892/ijo_00000443

\begin{abstract}
In our previous study, we successfully treated an established C6 brain tumor using neural stem cells transduced with the herpes simplex virus-thymidine kinase gene (HSVtk) and ganciclovir in the rat. In the present study, we investigated the use of mesenchymal stem cells (MSCs), obtained from adult rats and transduced with HSVtk (MSCtk cells), instead of neural stem cells because MSCs are much easier to obtain from the adult subjects. Those cells were used for in vitro coculture study and in vivo co-implantation study with C6 rat glioma cells to examine bystander tumoricidal effect, which revealed a sufficient bystander effect and only 1/32 MSCtk cells were needed for complete tumor eradication. In vitro bystander effect was also observed in a real-time fashion using a culture microscope and it was shown that only tumor cells that had contact with MSCtk cells died. In vivo treatment study of an established C6 brain tumor with an intratumoral injection of MSCtk cells followed by systemic ganciclovir administration demonstrated a significant reduction of the tumor size and a significant survival prolongation. The treatment strategy using MSCtk and ganciclovir (MSCtk therapy) is more feasible and practical for clinical application than the method using neural stem cells.
\end{abstract}

\section{Introduction}

Glioblastoma is the most common malignant tumor of the brain. Standard therapy for intracranial gliomas centers extensive on surgical resection followed by adjuvant radiochemotherapy. Recently, gross total tumor resection becomes possible even when the tumor locates near the eloquent brain

Correspondence to: Dr Hiroki Namba, Department of Neurosurgery, Hamamatsu University School of Medicine, 1-20-1 Handayama, Higashi-ku, Hamamatsu 431-3192, Japan

E-mail: hnamba@hama-med.ac.jp

Present address: ${ }^{3}$ Department of Neurosurgery, Shengjing Hospital of China Medical University, Shenyang 110004, P.R. China

Key words: mesenchymal stem cell, glioma, suicide gene therapy, bystander effect, herpes simplex virus thymidine kinase regions by using a neuronavigation system and multimodal techniques of neurological functional monitoring. However, because this tumor is highly invasive and diffusely infiltrates into the brain tissue, surgical resection is almost always followed by regrowth of tumor cells residing in adjacent brain regions (1). Furthermore, this tumor is highly resistant to radiation and chemotherapy (2). The median survival of the patients with glioblastoma is about one year and only a little improvement has been achieved during the past 3 decades (3). Development of novel treatment strategies are urgently needed, especially targeting these residual tumor cells disseminated from the main tumor mass.

The gene therapies using the suicide genes have been so designed to treat locally-invaded glioma cells because these therapies have a very attractive property called the 'bystander effect', where brain tumor cells that are not transduced with the suicide gene also become sensitive to prodrugs and eliminated along with suicide gene-transduced cells (4). Though the suicide gene therapy with the herpes simplex virus-thymidine kinase (HSVtk) gene and a prodrug, ganciclovir (GCV) have been clinically tested in many institutions, the efficacy has been limited because of the short survival of viral vectors and low migratory activity of vector producing cells (5).

In order to expand treatment area by the HSVtk/GCV gene therapy, we have been using neural stem cells (NSCs) that have potent migratory activity especially toward brain lesions such as tumors (6-8). In our previous studies, rat brain tumors were successfully treated through the bystander effect by an intratumoral injection of NSCs transduced with HSVtk gene (NSCtk cells) followed by systemic GCV administration and this bystander effect was still potent when NSCtk cell were injected at distant intracranial sites from the tumor $(9,10)$. Therefore, the HSVtk/GCV gene therapy using NSCtk cells is quite promising to proceed to clinical trials. However, it is not so easy to obtain NSCs from the glioma patients because interventions are required. Recently, neural stem cell-like cells have been isolated from human adult bone marrow cells and those cells show potent migratory activity in the brain toward glioma (11-16). These cells, called mesenchymal stem cells (MSCs), can be gathered more easily. In the present study, we evaluated the possibility of using MSCs obtained from adult rat bone marrow instead of NSCs obtained from fetal rat brain in the HSVtk/GCV gene therapy of rat gliomas. 


\section{Materials and methods}

Isolation of mesenchymal stem cells (MSCs) from SpragueDawley rat. All following experiments were performed according to the Rules of Animal Experimentation and the Guide for the Care and Use of Laboratory animals of the Hamamatsu University School of Medicine. Sprague-Dawley (SD) rat (9-weeks old, Nippon SLC, Hamamatsu, Japan) was sacrificed with ether. The pelt of rat was made thoroughly wet with $70 \%$ isopropyl alcohol and femurs and tibias were removed by severing them from the animal at the hip and ankle, respectively. The interior of the marrow shaft was exposed by trimming the ends of the long bones and the marrow tissue was flushed out using a 21-gauge needle attached to a 5-ml syringe. A single cell suspension was obtained by gently aspirating the tissue several times using the same needle and syringe in $5 \mathrm{ml}$ murine MSC growth medium (MMSCGM; Stem Cell Technologies Inc., B.C, Canada) and washed one time with $10 \mathrm{ml}$ fresh MMSCGM and incubated at $37^{\circ} \mathrm{C}$ under $5 \% \mathrm{CO}_{2}$. The non-adherent cells were removed by replacing the medium $24 \mathrm{~h}$ after the initial culture. The residual attached cells were maintained at $37^{\circ} \mathrm{C}$ in $5 \% \mathrm{CO}_{2}$ by exchanging the medium with fresh medium at 5-day intervals. These cells are designated as mesenchymal stem cells (MSCs) in the present study.

Establishment of the MSCs with the HSVtk gene. The HSVtk retrovirus-producing cells (PA317; mouse fibroblast cell line with HSVtk gene) were kindly provided by Genetic Therapy Inc. (Gaithersburg, MD). After culturing the PA317 cells in DMEM for $48 \mathrm{~h}$, the supernatant was collected.

After removing non-adherent cells $24 \mathrm{~h}$ following the initial culture, $1 \mathrm{ml}$ of the supernatant of HSVtk retrovirus was added into the $25-\mathrm{cm}^{2}$ tissue culture flask with $1 \mathrm{ml}$ MMSCGM. The MSCs were incubated in the presence of $8 \mu \mathrm{g} / \mathrm{ml}$ Polybrene (Aldrich Chemical Company Inc., Milwaukee, WI) for $6 \mathrm{~h}$. After washing three times, the cells were maintained with fresh MMSCGM. The drug selection with $100 \mu \mathrm{g} / \mathrm{ml} \mathrm{G} 418$ (Sigma-Aldrich Japan K.K., Tokyo, Japan) was performed for 4 weeks. The drug-resistant cells were collected and cultured in MMSCGM (containing 100 $\mu \mathrm{g} / \mathrm{ml} \mathrm{G} 418$ ) to prepare sufficient numbers of cells. The drugresistant cells (HSVtk gene-transduced MSCs; MSCtk cells) were used for futhere experiments.

In vitro bystander effect on rat C6 glioma cells. The C6 rat glioma cells were purchased from ATCC (Manassas, VA). The cells $\left(5 \times 10^{3}\right)$ were co-cultured with various numbers of MSCtk cells (MSCtk:C6 ratios = 1:1, 1:4, 1:16, 1:32, 1:64 and 1:128) or without MSCtk cells (C6 alone) in MMSCGM with/without $1 \mu \mathrm{g} / \mathrm{ml} \mathrm{GCV}$ for 7 dsays and without GCV afterward in a 24-well tissue culture plate, in order to determine the lowest necessary number of MSCtk cells which could provide sufficient anti-tumor effect. The conditional medium was changed every 2 days and the number of living cells was counted under a phase-contrast microscope on days 7 and 14 . Living cell numbers in 3 fields for 3 wells were averaged.

Moreover, the real-time bystander effect was observed with a culture microscope (BioStation IM, Nikon, Japan). MSCs were obtained from the GFP rat [SD-Tg(CAG-EGFP)] and GFP-MSCtk cells were similarly made. GFP-MSCtk and C6 cells were co-cultured (cell ratio $=1: 1$ ) in the medium containing $1 \mu \mathrm{g} / \mathrm{ml} \mathrm{GCV}$. Living cell numbers in 3 fields for 3 wells were averaged.

\section{Treatment of intracranial C6 tumors in SD rats through the} bystander effect generated with intratumoral injection of MSCtk cells followed by GCV administration. Studies were performed on adult male SD rats weighing $300 \pm 20 \mathrm{~g}$. Following initial induction with $4 \%$ isoflurane, rats were anesthetized intraperitoneally with chloral hydrate $(400 \mathrm{mg} / \mathrm{kg}$ ) and placed in a stereotaxic apparatus (Narishige Scientific Instrument Lab., Tokyo, Japan). After incising the scalp, a burr hole was made at $1 \mathrm{~mm}$ rostral and $3 \mathrm{~mm}$ right from bregma. The C6 cells $\left(1 \times 10^{5}\right)$ in $10 \mu$ DMEM were implanted from the burr hole by 23 -gauge needle to the point of $5 \mathrm{~mm}$ ventral from the dura by using a micro-injector $(1 \mu \mathrm{l} / \mathrm{min})$ on day 0 . After injection, we waited $5 \mathrm{~min}$ and removed the needle slowly during the next $5 \mathrm{~min}$. On day 3, we injected MSCtk cells $\left(1 \times 10^{5}\right)$ in $10 \mu 1$ MMSCGM using the same method through the same burr hole. Half of the rats were intraperitoneally administered with GCV at a dose of $15 \mathrm{mg} / \mathrm{kg}$, twice daily from day 4 for 7 days (GCV group, $n=12$ ) or with saline (saline group, $\mathrm{n}=12$ ). Another control group was not injected with MSCtk and not administered with GCV (C6 group, $n=12$ ).

Half of the rats for each group $(n=6)$ were sacrificed on day 20 for histological examination. Serial coronal brain sections were obtained and stained with hematoxylin and eosin. Tumor volume was calculated as longer diameter $\mathrm{x}$ shorter diameter $2 / 2$ in the section with maximum tumor size. The other half $(n=6)$ were used for the survival study. Survival was analyzed by a log-rank test based on the Kaplan-Meier test using SigmaStat 3.0 software.

\section{Results}

In vitro bystander effect on rat C6 glioma cells. Nearly no viable cells were observed when cultured in the medium containing $1 \mu \mathrm{g} / \mathrm{ml} \mathrm{GCV}$ at the MSCtk:C6 ratios from 1:1 to $1: 32$ on day 7 and the C6 cells did not proliferate after GCV had been removed (day 14, Fig. 1). C6 proliferation was not inhibited by addition of MSCtk cells when the medium did not contain GCV (data not shown). At MSCtk:C6 ratios of $1: 64$ and $1: 128$, tumor proliferation was significantly suppressed (Fig. 1, p<0.01) compared with corresponding controls culture in the medium without GCV (data not shown), though we could not completely eradiate C6 cells.

The real-time in vitro bystander effect was observed with the culture microscope. GFP-MSCtk cells were cocultured with the same number of C6 cells in the medium containing $1 \mu \mathrm{g} / \mathrm{ml} \mathrm{GCV}$. During the first $24 \mathrm{~h}, \mathrm{C} 6$ cells vividly proliferated while green-colored GFP-MSCtk cells did not. (Fig. 2a-c). However, when C6 cells proliferated more and made contact with GFP-MSCtk cells, C6 cells showed apoptotic cell death due to bystander effect (Fig. 2d and e). At $72 \mathrm{~h}$ after co-culturing, C6 cells were completely eradicated, while some good-shaped green-colored GFPMSCtk cells were still observed (Fig. 2f).

Time courses of GFP-MSCtk and C6 cell numbers are shown as the ratio to the cell numbers at $0 \mathrm{~h}$ (Fig. 3). The 


\section{In vitro bystander effect at different ratios}

GCV: $1 \mu \mathrm{g} / \mathrm{ml}$ for 7 days

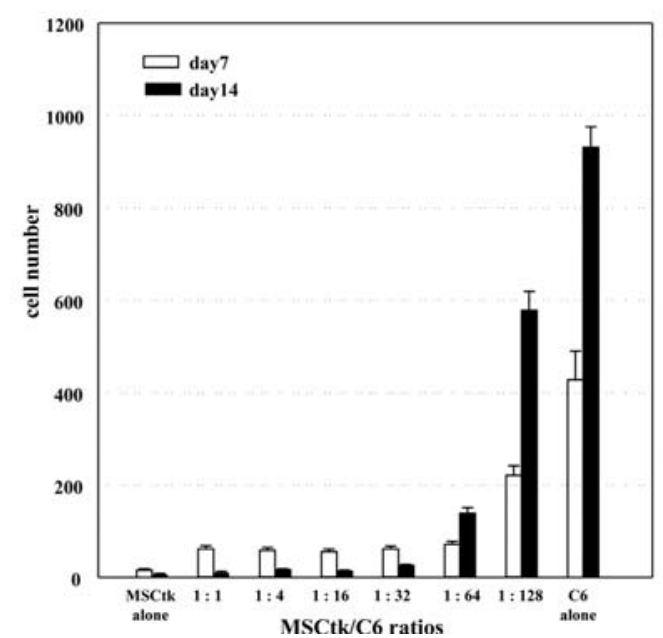

Figure 1. In vitro bystander effect between MSCtk and C6 cells at various ratios. The $\mathrm{C} 6$ cells $\left(5 \times 10^{3}\right)$ were co-cultured with various numbers of MSCtk cells (MSCtk:C6 = 1:1, 1:4, 1:16, 1:32, 1:64 and 1:128) or without MSCtk cells (C6 alone) and MSCtk alone in MMSCGM with $1 \mu \mathrm{g} / \mathrm{ml} \mathrm{GCV}$ during the first 7 days and without GCV another 7 days in a 24-well tissue culture plate. Living cell numbers in 3 fields for 3 wells were averaged (mean \pm SD). Nearly no viable cells were observed at the MSCtk:C6 ratios from 1:1 to $1: 32$ on both days 7 and 14. Significant growth inhibition was also observed at the MSCtk:C6 ratios of 1:64 to 128 on days 7 and 14 ( $\mathrm{p}<0.01)$ compared with corresponding controls culture in the medium without GCV (data not shown).

number of C6 cells increased during the first $12 \mathrm{~h}$, and then steeply decreased afterward to reach complete eradication at $48 \mathrm{~h}$. The number of GFP-MSCtk cells remained stable during the first $40 \mathrm{~h}$, and then gradually decreased afterward. At $72 \mathrm{~h}$, some GFP-MSCtk cells were still alive.

\section{Transition of number of cells under a culture microscope}

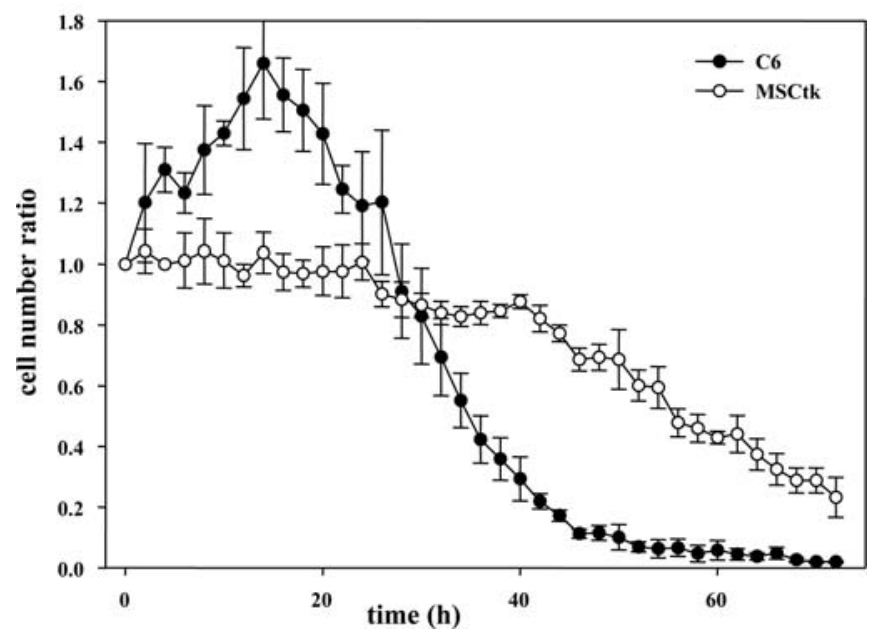

Figure 3. In vitro changes in cell numbers of GFP-MSCtk and C6 cells GFP-MSCtk and C6 cells were counted every $2 \mathrm{~h}$ in the methods described in the text and the cell number ratios to the initial cell number (time $0 \mathrm{~h}$ ) were plotted. Living cell numbers in 3 fields for 3 wells were averaged (mean $\pm \mathrm{SD}$ ). C6 cell number rapidly increased during the first $12 \mathrm{~h}$ and then decreased to almost zero at $48 \mathrm{~h}$. On the contrary, GFP-MSCtk cell number remained stable for the first $40 \mathrm{~h}$ then gradually decreased. Some GFP-MSCtk cells were still alive at $72 \mathrm{~h}$.

Treatment of intracranial C6 tumors in SD rats through the bystander effect generated with intratumoral injection of MSCtk cells followed by GCV administration. Treatment of the established C6 tumor with the combination of intratumoral injection of MSCtk cells followed by intraperitoneal GCV administration (GCV group) significantly reduced the size

\section{In vitro bystander effect $\underset{\substack{\text { MSCk: } \mathrm{CC}=1: 1 \\ \mathrm{GCV}: 1 \mathrm{\mu g} / \mathrm{ml}}}{2}$}

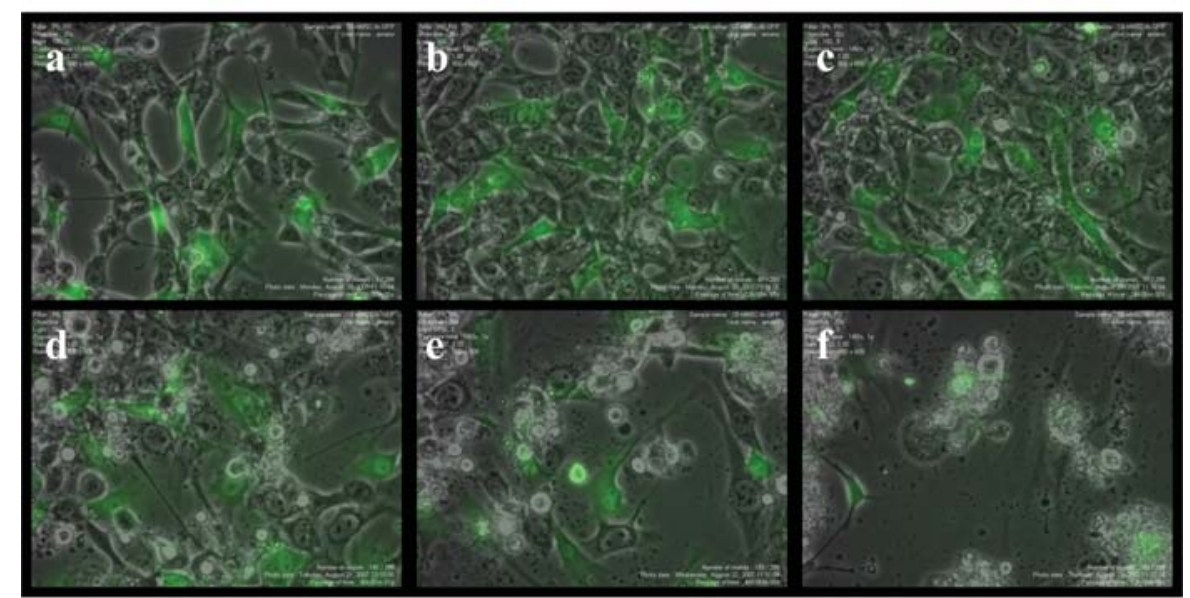

\section{a:0, b:12, c:24, d:36, e:48, f:72 hr}

Figure 2. In vitro bystander effect observed under a culture microscope. The real-time in vitro bystander effect was observed with the culture microscope. GFP-MSCtk cells were co-cultured with the same number of C6 cells in the medium containing $1 \mu \mathrm{g} / \mathrm{ml}$ GCV. GFP-MSCtk cells survived for at least 2 or 3 days. All the C6 cells showed apoptotic death after contact with MSCtk cells (a, 0; b, 12; c, 24; d, 36; e, 48; f, 72 h after co-culturing). 


\section{In vivo bystander effect}
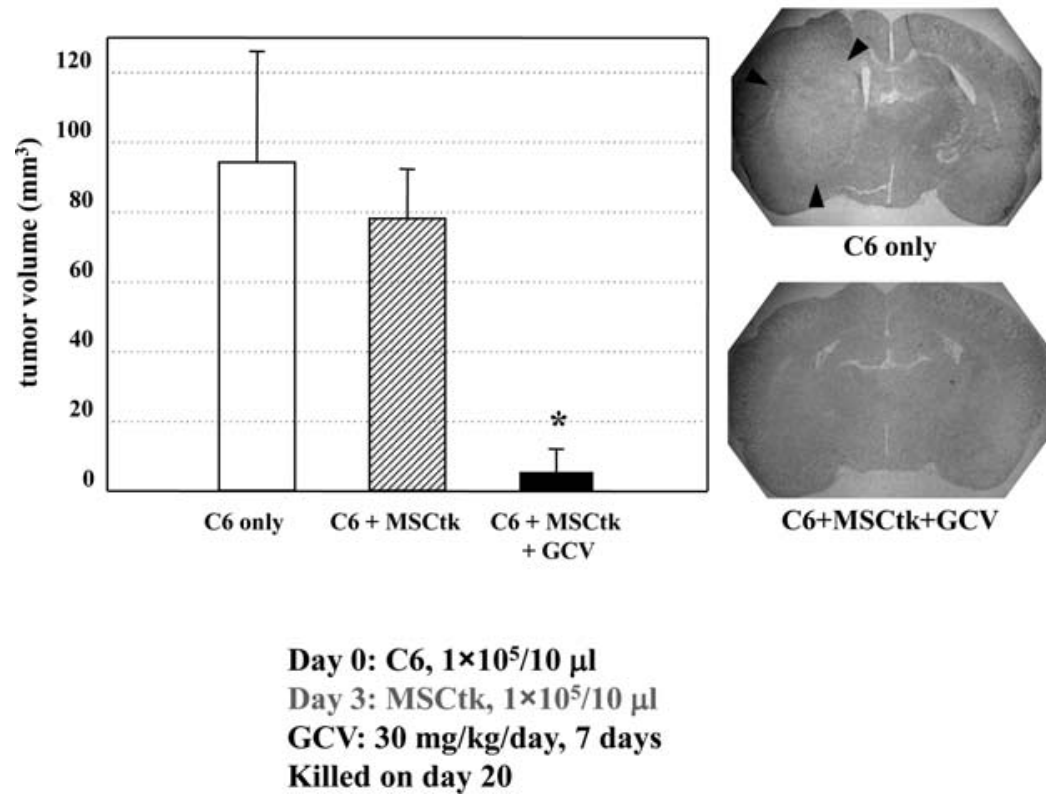

C6 only

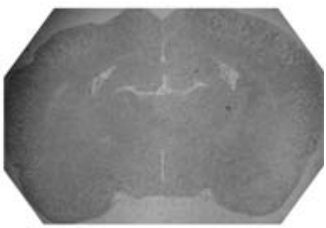

C6+MSCtk+GCV

Figure 4. Treatment of intracranial C6 tumors by intratumoral injection of MSCtk cells and GCV. No tumors or only small tumors were observed in the GCV group (C6 + MSCtk + GCV) on day 20 and the size of the tumors in this group was significantly smaller than those in the saline group (C6 + MSCtk) and C6 only group (left panel; ${ }^{\mathrm{p}} \mathrm{p}<0.01$ ). Representative coronal sections are demonstrated (right panel).

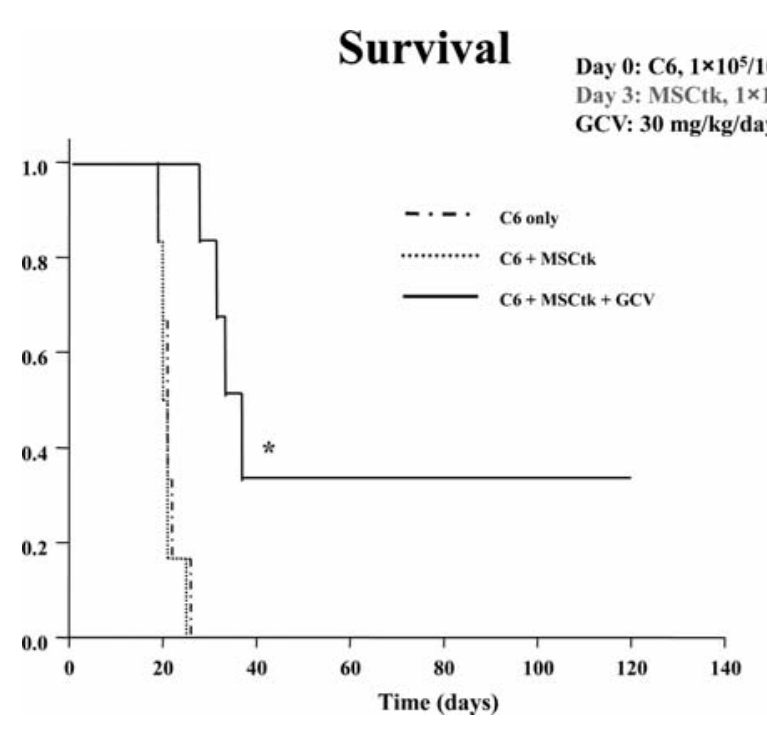

Figure 5. Survival curves. Kaplan-Meier survival curves of the rats in the C6 only group, the saline group (C6 + MSCtk), and the GCV group (C6 + MSCtk + GCV). All the rats in the C6 only and saline groups died in about 3 weeks. The rats in the GCV group survived significantly longer than those in the other two groups $\left({ }^{*} \mathrm{p}<0.01\right)$.

of tumor examined on day 20 as compared to those of rats treated with MSCtk injection only (saline group) and the C6 group (Fig.4 left panel, p<0.01). No tumors were observed on day 20 in 2 out of 6 rats, and only small tumors, in the other 4 rats. No significant differences were observed between the sizes of tumors in the saline group (C6 + MSCtk) and in the
C6 group (Fig. 4). There were also no differences between the sizes of C6 tumors treated with and without GCV (data not shown). Representative coronal sections from the C6 group (large tumor) and the GCV group (no tumor) were demonstrated (Fig. 4, right panel).

All the rats in the C6 group and the saline group died in about 3 weeks (Fig. 5). The rats in the GCV group (treated with MSCtk cells and GCV) survived significantly longer than those in the other two groups (Fig. 5, p<0.01). Two out of 6 rats in the GCV group survived $>120$ days and considered to be cured. The other 4 rats in the GCV group also survived longer but finally died of brain tumor.

\section{Discussion}

In our previous studies, we have already demonstrated that established rat C6 brain tumors were successfully treated through the bystander effect generated by an intratumoral injection of NSCtk cells followed by systemic GCV administration, so-called NSCtk therapy (10). Some of the studies have shown active tropism of NSCs toward brain tumors even when NSCs are implanted in the opposite side of cerebral hemisphere as in our previous study (9). However, it is not so easy to obtain sufficient amount of NSCs from the glioma patients, and therefore, NSCtk therapy is not very practical for clinical use. In 2003, Lee et al demonstrated that neural stem-like cells can be obtained from human adult bone marrow and those cells can migrate toward distant sites of brain injury and tumor in vivo, where they differentiate and express therapeutic transgenes (11). Since then, several studies of treatment of experimental brain tumors using 
genetically modified so-called MSCs have been published $(12,13)$. Because we have long been working on gene therapies using the HSVtk/GCV system $(17,18)$, we investigated here the possibility of treating rat gliomas with HSVtk trsnsduced MSCs and GCV (MSCtk therapy) and compared the efficacy with that of our previous NSCtk therapy.

We demonstrated, in the present in vitro co-culture study, that no tumors were observed at MSCtk:C6 cell ratios from $1: 1$ to $1: 32$ in the culture medium containing $1 \mu \mathrm{g} / \mathrm{ml} \mathrm{GCV}$ (Fig. 1). Since this concentration of GCV in the medium has no effect on C6 proliferation, this effect is due to the bystander effect between MSCtk and C6 cells. Even at the MSCtk:C6 cell ratios of 1:64 and 1:128, significant bystander tumoricidal effect was observed (Fig. 1). These results suggest that the bystander effect between MSCtk and C6 cells is as potent as that between NSCtk and C6 cells shown in our previous study (19). Since MSCs are much easier to obtain from adult subjects, MSCtk therapy would be more feasible for clinical application than NSCtk therapy.

In the real-time observation in the co-culture experiment of GFP-MSCtk and C6 using the culture microscope, the number of $\mathrm{C} 6$ cells increased during the first $12 \mathrm{~h}$, during which C6 cells in the dish were not so confluent, then C6 cell number steeply decreased (Figs. 2 and 3). This is mainly due to increased cell-to-cell contact in confluent C6 cell culture conditions, because the bystander effect in the HSVtk/GCV system is generated only when tumor cells have contact with HSVtk-positive cells (20). MSCtk cells do not die as long as $72 \mathrm{~h}$ even in the medium containing GCV (Figs. 2 and 3). This is mainly due to low proliferation activity of MSCs because GCV only kills proliferating cells and does not kill postmitotic cells (21). This low proliferation activity of MSCs may be disadvantageous because the MSCtk:tumor cell ratio lowered with time. On the contrary, it is advantageous because MSCtk cells survive for a sufficient period for killing surrounding tumor cells in the presence of GCV. This information seems very important when we make a clinical protocol of MSCtk therapy especially when we determine the timing of GCV administration after the MSCtk injection. As far as the C6 rat brain tumor model is concerned, GCV should be given immediately after MSCtk injection because C6 proliferation is so rapid and the MSCtk:tumor cell ratio steeply decreased during the time before GCV administration. However, in the case of human glioblastomas, tumor cell proliferation is not as rapid as that of C6 cells, and therefore, the optimal timing of GCV administration may be a little later. In the treatment of human gliomas, it would be ideal if we could know the distribution and amount of exogenouslyadministered treatment cells (MSCtk, NSCtk, so on). Recently, for tracing exogenously-administered MSCs, magnetic resonance imaging and positron emission tomography have been applied using iron-labeled MSCs $(15,22)$ and thymidine kinase reporter gene (21,23-26), respectively.

In vivo experiment in Sprague-Dawley rats for treating intracranial C6 tumors through the bystander effect generated with the intratumoral injection of MSCtk cells and GCV administration resulted in a significant tumor growth suppression and a significant prolongation of survival time (Figs. 4 and 5). Two out of 6 rats in the GCV group survived $>120$ days and considered to be cured. These results are quite similar to those using NSCtk cells (10). Again, because of easier accessibility of MSCs than NSCs, MSCtk therapy would be more feasible for clinical application than NSCtk therapy. It is reported that MSCs can also home intracranial tumor sites when intravascularly administered $(13,15)$. Uchibori and colleagues also showed a significant antitumor effect by intravenous injection of retroviral vector-producing MSCs expressing HSVtk (27). However, to generate sufficient bystander effect, both the MSCtk:tumor cell ratio and tumor cell-to-HSVtk positive cell contact should be sufficiently high. For these reasons, direct administration on the surface of the tumor-removal cavity or intratumoral administration into small tumor nodules may be the methods to use for the first protocols against recurrent gliomas.

We have been using the HSVtk/GCV system because tumor growth suppression ability is most prominent and rapid in this system as compared with the other gene therapy systems. The other reason is the safety issue for normal brain tissues. As shown in the present study, the bystander effect in the HSVtk/GCV system is generated only when HSVtk-negative dividing cells have contact with HSVtk-positive cells. Therefore, MSCtk cells migrating toward the tumor cells kill only proliferating tumor cells that have had contact with MSCtk cells. After MSCtk therapy, we have observed that normal brain tissues are not injured except the needle tract used for the cell injections (data not shown). Experimental studies using MSCs transduced with various therapeutic genes, such as tumor necrosis factor-related apoptosis-inducing ligand $(11,28)$, interferon- $\beta(13,29)$, interleukin-2 $(12)$, interleukin-23 (14), and cytosine deaminase (30), as well as thymidine kinase $(31,32)$, have been reported. It is also attractive to investigate combinations of these cytokine and suicide gene therapy systems.

Migratory activity of MSCs against tumor cells has been reported using the method injecting MSCs into the contralateral hemisphere to the tumor cell injection. Many MSCs have been shown to migrate and home around the tumor implanted in the contralateral hemisphere along with the corpus callosum within a week as in the case of NSCs (9). Because gliomas have an infiltrative tendency to the surrounding brain tissues and treatment of those satellite tumors as well as the main tumor mass is the key for successful treatment. The mechanisms of tumor homing activity of MSCs and NSCs have been also widely investigated. Interleukin-8, transforming growth factor-ss1 and neurotrophin-3, vascular endothelial growth factor are some of the candidate molecules to attract MSCs (33). Elucidation of the precise mechanism with which tumor cells attract MSCs may lead to a more efficient clinical protocol. Enhancement of the bystander effect by using compounds such as sulfasalazine (34), connexin (35-38), and scopadulciol (39) could be another strategy.

In conclusion, MSCtk therapy has been shown to have similar potency for the treatment of experimental rat glioma as NSCtk therapy, whose efficacy has been already proved in our previous studies. Since MSCs are more easily accessible than NSCs, MSCtk therapy is clinically more feasible than NSCtk therapy. Obviously, further studies for elucidation of mechanism underlying MSC movement and bystander effect potential are necessary before making a precise clinical protocol for MSCtk therapy. 


\section{Acknowledgments}

This work was supported in part by Japan Society for the Promotion of Science grant 20791005 (S. Amano) and 18090394 (H. Namba).

\section{References}

1. De Angelis LM: Brain tumors. N Engl J Med 344: 114-123, 2001.

2. Lefranc F, Brotchi J and Kiss R: Possible future issues in the treatment of glioblastomas: special emphasis on cell migration and the resistance of migrating glioblastoma cells to apoptosis. J Clin Oncol 23: 2411-2422, 2005.

3. Stewart LA: Chemotherapy in adult high-grade glioma: a systematic review and meta-analysis of individual patient data from 12 randomised trials. Lancet 359: 1011-1018, 2002.

4. Culver KW, Ram Z, Wallbridge S, Ishii H, Oldfield EH and Blaese RM: In vivo gene transfer with retroviral vector-producer cells for treatment of experimental brain tumors. Science 256: 1550-1552, 1992.

5. Barzon L, Zanusso M, Colombo F and Palu G: Clinical trials of gene therapy, virotherapy, and immunotherapy for malignant gliomas. Cancer Gene Ther 13: 539-554, 2006.

6. Aboody KS, Brown A, Rainov NG, et al: Neural stem cells display extensive tropism for pathology in adult brain: evidence from intracranial gliomas. Proc Natl Acad Sci USA 97: 12846-12851, 2000

7. Ehtesham M, Kabos P, Kabosova A, Neuman T, Black KL and Yu JS: The use of interleukin 12-secreting neural stem cells for the treatment of intracranial glioma. Cancer Res 62: 5657-5663, 2002.

8. Wennersten A, Meier X, Holmin S, Wahlberg L and Mathiesen T: Proliferation, migration, and differentiation of human neural stem/progenitor cells after transplantation into a rat model of traumatic brain injury. J Neurosurg 100: 88-96, 2004.

9. Li S, Gao Y, Tokuyama T, et al: Genetically engineered neural stem cells migrate and suppress glioma cell growth at distant intracranial sites. Cancer Lett 251: 220-227, 2007.

10. Li S, Tokuyama T, Yamamoto J, Koide M, Yokota N and Namba H: Bystander effect-mediated gene therapy of gliomas using genetically engineered neural stem cells. Cancer Gene Ther 12: 600-607, 2005.

11. Lee J, Elkahloun AG, Messina SA, et al: Cellular and genetic characterization of human adult bone marrow-derived neural stem-like cells: a potential antiglioma cellular vector. Cancer Res 63: 8877-8889, 2003.

12. Nakamura K, Ito Y, Kawano Y, et al: Antitumor effect of genetically engineered mesenchymal stem cells in a rat glioma model. Gene Ther 11: 1155-1164, 2004.

13. Nakamizo A, Marini F, Amano T, et al: Human bone marrowderived mesenchymal stem cells in the treatment of gliomas. Cancer Res 65: 3307-3318, 2005.

14. Yuan X, Hu J, Belladonna ML, Black KL and Yu JS: Interleukin-23-expressing bone marrow-derived neural stem-like cells exhibit antitumor activity against intracranial glioma. Cancer Res 66: 2630-2638, 2006.

15 . Wu X, Hu J, Zhou L, et al: In vivo tracking of superparamagnetic iron oxide nanoparticle-labeled mesenchymal stem cell tropism to malignant gliomas using magnetic resonance imaging. Laboratory Investigation. J Neurosurg 108: 320-329, 2008 .

16. Bexell D, Gunnarsson S, Tormin A, et al: Bone marrow multipotent mesenchymal stroma cells act as pericyte-like migratory vehicles in experimental gliomas. Mol Ther 17: 183-190, 2009.

17. Namba H, Iwadate Y, Tagawa M, et al: Evaluation of the bystander effect in experimental brain tumors bearing herpes simplex virus-thymidine kinase gene by serial magnetic resonance imaging. Hum Gene Ther 7: 1847-1852, 1996.

18. Namba H, Tagawa M, Iwadate Y, Kimura M, Sueyoshi K and Sakiyama S: Bystander effect-mediated therapy of experimental brain tumor by genetically engineered tumor cells. Hum Gene Ther 9: 5-11, 1998

19. Li S, Tokuyama T, Yamamoto J, Koide M, Yokota N and Namba H: Potent bystander effect in suicide gene therapy using neural stem cells transduced with herpes simplex virus thymidine kinase gene. Oncology 69: 503-508, 2005.
20. Iwadate Y, Namba H, Tagawa M, Takenaga K, Sueyoshi K and Sakiyama S: In vivo bystander effect in the intracranial model with rat glioma cells reflects the clonal difference of HSV-TK positive cells. Int J Oncol 9: 521-525, 1996.

21. Miletic H, Fischer YH, Giroglou T, et al: Normal brain cells contribute to the bystander effect in suicide gene therapy of malignant glioma. Clin Cancer Res 13: 6761-6768, 2007.

22. Farrell E, Wielopolski P, Pavljasevic P, et al: Effects of iron oxide incorporation for long term cell tracking on MSC differentiation in vitro and in vivo. Biochem Biophys Res Commun 369: 1076-1081, 2008.

23. Roelants V, Labar D, De Meester C, et al: Comparison between adenoviral and retroviral vectors for the transduction of the thymidine kinase PET reporter gene in rat mesenchymal stem cells. J Nucl Med 49: 1836-1844, 2008.

24. Xiong Z, Cheng Z, Zhang X, et al: Imaging chemically modified adenovirus for targeting tumors expressing integrin alphavbeta 3 in living mice with mutant herpes simplex virus type 1 thymidine kinase PET reporter gene. J Nucl Med 47: 130-139, 2006

25. Yaghoubi SS, Barrio JR, Namavari M, et al: Imaging progress of herpes simplex virus type 1 thymidine kinase suicide gene therapy in living subjects with positron emission tomography. Cancer Gene Ther 12: 329-339, 2005.

26. Jacobs AH, Winkeler A, Hartung M, et al: Improved herpes simplex virus type 1 amplicon vectors for proportional coexpression of positron emission tomography marker and therapeutic genes. Hum Gene Ther 14: 277-297, 2003.

27. Uchibori R, Okada $\mathrm{T}$, Ito $\mathrm{T}$, et al: Retroviral vector-producing mesenchymal stem cells for targeted suicide cancer gene therapy. J Gene Med 11: 373-381, 2009.

28. Kim SM, Lim JY, Park SI, et al: Gene therapy using TRAILsecreting human umbilical cord blood-derived mesenchymal stem cells against intracranial glioma. Cancer Res 68: 9614-9623, 2008.

29. Studeny M, Marini F, Champlin R, Zompetta C, Fidler I and Andreeff M: Bone marrow-derived mesenchymal stem cells as vehicles for interferon-beta delivery into tumors. Cancer Res 62: 3603-3608, 2002.

30. Kucerova L, Altanerova V, Matuskova M, Tyciakova S and Altaner C: Adipose tissue-derived human mesenchymal stem cells mediated prodrug cancer gene therapy. Cancer Res 67: 6304-6313, 2007.

31. Ribot E, Bouzier-Sore AK, Bouchaud V, et al: Microglia used as vehicles for both inducible thymidine kinase gene therapy and MRI contrast agents for glioma therapy. Cancer Gene Ther 14: 724-737, 2007.

32. Miletic H, Fischer Y, Litwak S, et al: Bystander killing of malignant glioma by bone marrow-derived tumor-infiltrating progenitor cells expressing a suicide gene. Mol Ther 15: 1373-1381, 2007.

33. Birnbaum T, Roider J, Schankin CJ, et al: Malignant gliomas actively recruit bone marrow stromal cells by secreting angiogenic cytokines. J Neurooncol 83: 241-247, 2007.

34. Robe PA, Nguyen-Khac MT, Lambert F, et al: Sulfasalazine unveils a contact-independent HSV-TK/ganciclovir gene therapy bystander effect in malignant gliomas. Int J Oncol 30: 283-290, 2007.

35. Jimenez T, Fox WP, Naus CC, Galipeau J and Belliveau DJ: Connexin over-expression differentially suppresses glioma growth and contributes to the bystander effect following HSV-thymidine kinase gene therapy. Cell Commun Adhes 13: 79-92, 2006.

36. Uhl M, Weiler M, Wick W, Jacobs AH, Weller $M$ and Herrlinger U: Migratory neural stem cells for improved thymidine kinase-based gene therapy of malignant gliomas. Biochem Biophys Res Commun 328: 125-129, 2005.

37. Burrows FJ, Gore M, Smiley WR, et al: Purified herpes simplex virus thymidine kinase retroviral particles: III. Characterization of bystander killing mechanisms in transfected tumor cells. Cancer Gene Ther 9: 87-95, 2002.

38. Namba H, Iwadate Y, Kawamura K, Sakiyama S and Tagawa M: Efficacy of the bystander effect in the herpes simplex virus thymidine kinase-mediated gene therapy is influenced by the expression of connexin 43 in the target cells. Cancer Gene Ther 8: 414-420, 2001.

39. Hayashi K, Lee JB, Maitani Y, Toyooka N, Nemoto H and Hayashi T: The role of a HSV thymidine kinase stimulating substance, scopadulciol, in improving the efficacy of cancer gene therapy. J Gene Med 8: 1056-1067, 2006. 